\title{
Molecular Modeling and Opioid Receptor Binding Affinity of New Substituted Morphine Derivatives
}

\author{
Mohammed Oday Ezzat, Basma M. Abd Razik
}

\begin{abstract}
In this paper, the outcome of the experimental investigation and the flow field development in the duct at supersonic Mach number of 1.2 is presented. The experiments were conducted at various NPR which covers the condition of correct expansion and under expansion. A Convergent-divergent (C-D) nozzle which is connected with the suddenly expanded duct of the diameter of $16 \mathrm{~mm}$ of area ratio 2.56. The recirculation zone is controlled by using the microjets of $1 \mathrm{~mm}$ of orifice diameter which are placed at 90 degrees interval at $6.5 \mathrm{~mm}$ from the central axis of the main jet. The L/D of the duct was used in the investigation was from 1 to 10 , and the NPR at which the experiments were conducted considered are in the range from 3 , $5,7,9$ and 11.
\end{abstract}

Keywords-CD Nozzle; Microjet; Wall Pressure; and Mach number.

\section{INTRODUCTION}

Torment considers asa big standard clinical trouble and it is the primary motivation inside the returned of why human beings required restorative interest and one of the mostprevailing situations that pronouncements performance and life pleasant. Albeit enough available assist with pain and pain relieving medicines are finished like narcotics or nonsteroidal calming pills (NSAIDs), but the large impediments of usage in remedy is applicable to their actual element results. The torment remedy is a functioning territory under scrutiny with the presence of numerous effective pharmacotherapy pills, but there may be additionally a need to find out new optionally available medications free of poor reactions in recent times, severa analysts and pharmaceutical organizations areinterested in planning and growing extra comfortable and step by step efficient medications to comfort ache(Yin et al., 2016).

The initiation of narcotic receptor via manner of endogenous or exogenous ligands is set up with large style of physiologicaland social influences which includeantinociceptive, absense of pain, anxiousness, results for respiration despair, sedation, rapture, gastrointestinal excursion restraint, and so on.(Al-Hasani and Bruchas, 2011).

There are fourmain types recognized about narcotic receptorssystems arranged by means of the usage of their coupling selectivity for unique types ofopioids, $\mu$ (for morphine), $\kappa$ (for ketocyclazocine), $\delta$ (distinguished in mouse vas deferens), and narcotic receptor like-1 (ORL1).

Revised Manuscript Received on April 12, 2019.

Mohammed Oday Ezzat, Department of Chemistry, College of Education for Women, University of Anbar, 31001, Ramadi, Anbar, Iraq (edw.mohamed_oday@uoanbar.edu.iq)

Basma M. Abd Razik, College of Pharmacy, Al-Mustansiriyah University, 10001, Baghdad, Iraq. (mohamed_oday@yahoo.com)
Amongst them, the $\mu$ receptor isconsiders to be ordinarily in fee of the remedy of opioidtolerance and antinociception(Pathan and Williams, 2012).Morphine is a function alkaloid separated and defined for the reason that over ninety years once more from opium poppy Papaver somniferum(Benyhe, 1994).For in keeping with years, morphine has been clinically utilized as a a success ache relieving drug for the drugs ofmoderate to extreme torment sensationviathe enactment of $\mu$ opioid receptor (MOR)(Spetea et al., 2013a).

The morphineskeleton and its subsidiaries analogs had been continuously below investigation and development all through the years. The precept effortbehindthe synthetical accomplishment is the look for an optionally to be had analogs of morphine that could enhance absense of ache without its signs suchlike clogging, breathing sadness, sedation, resistance, and the maximum sizable compulsion effect(Skolnick and Volkow, 2016; Nyssen et al., 2018).Moreover, the morphinan framework has the foundation of promising new treatment and ligands development with preferred pharmacological movement required for patient use or arranged as research path to find narcotic pharmacology with the useful resource of in silico, in vitro and in vivo(Fürst and Hosztafi, 2008; Lewis and Husbands, 2010; Lattanzi et al., 2018).

Framework leaping (lead or atomic bouncing) is a slicing facet approach in the place of hypothetical healing era that alludes to the search for logo spanking new debris with better or comparative bioactivities to the first atoms structures(Zhao, 2007). To carry out this cause, numerous computational methodologies have been linked to supply multi debris structures with excellent or comparable bioactivities via substitution of selected concoction bunch in given sub-atomic form of intrigue (Brown and Jacoby, 2006). Those methodologies comprise all yet again atomic plan, pharmacophore are searching for, virtual screening, topology likeness and shape similitude search(Klebe, 2006; Eckert and Bajorath, 2007; Khedkar et al., 2007).These kind of frameworks bouncing strategies have been established as gifted apparatuses in sub-atomic designin many audit articles(Algamal et al., 2015; Rensi and Altman, 2017). The points of platform substitution are to mild up numerous herbal, concoction, or maybe intellectualproperties troubles identified with the framework of essential lead association in a remedy revelation examines. Mainly, platform substitution is commonly used to enhance the ADMET 
(assimilation, distribution,metabolism, discharge, and risk) profile like solvency, metabolic, or lethality to beautify strength or selectivity towards the intention movement thru making association of mixes as a almost same to of the covered compound(Lo et al., 2018). On this paintings, a improvement of morphine analogs were collected from literatures(Neumeyer et al., 2001; Dumitrascuta et al., 2017) and hypothetically observe for limiting fondness within the direction of $\mu$ narcotic receptor. Also, a model assessment and platform bunch substitution have been connected to provide new morphine analogs with promising antinociceptive movement.

\section{COMPUTATIONAL TECHNIQUE}

An aggregate of 27 morphine analogs structures have been accrued from literary works and the 3-d compliances of allanalogues had been drawn thru utilising ChemDraw16.Zero software (ChemDraw, 2016). Subsequent, geometry streamlining were connected by means of the use of MM+ electricity field using Hyperchem rendition eight.0 (Gainesville, 2009)then spared as .Mol record organization. Moreover, new geometry improvement by using semi-observational approach modified into executed for RM1 (Recife version 1)(Allinger, 1977; Rocha et al., 2006). Beginning there the maximum minimal energy conformers of every clean come to be spared as .Sdf characteristic for the remaining strengthen of enhancement with the aid of the usage of Spartan 14.0 beneath home windows (Spartan, 2014) with Monte Carlo approach and oppressed with 100 cycles of streamlining, one thousand interactions(Cohen, 1996). Atomic demonstrating and subatomic docking study have been completed making use of drift docking venture of Schrodinger (Maestro 10.1) programming (Schrodinger, 2015) for the readiness, minimization and docking concentrates jogging on home home windows 7 service \% 1 operating framework on Dell Precision T-1570 laptop (Intel(R) center(TM) i7 CPU 866 (a) 3.60GHz, 12 GB RAM, 1 TB HD). The gem structures of dynamic $\mu$ narcotic receptor modified into gotten from Protein statistics financial institution (PDB: 5C1M) with crystallographic desires of 2.1. The receptor readiness (ProPrep) became applied to beautify and limit the protein. This technique stuffed in any lacking circles and set up the receptor with a perfect excessive form. The primary BU72 ligands become evacuated and spared into the PDB documents via the usage of the use of the Maestro GUI. The ligand association (LigPrep) changed into implemented before docking listen to differentiate the potential ionization state, together with hydrogen molecule and to perform low vitality variations of ligand making use of OPLS 2005 electricity subject. The receptor lattice box changed into selected to at least one. $00 \AA$ with a fractional nuclear price of zero.25. At that point, the first ligand docked again adaptably usingGlide-extra exactness (XP) reenactments to the evaluating restricting pocket inside the receptor lattices. For the duration of the docking technique, the receptor changed into held inflexible whilst ligands have been adaptable. The fantastic docked posture and RMSD a few of the precious stone form and the docked posture have been saved.In request to create a few analogs with deferent piece, mechanized segment substitution become linked. All analogs had been created thru custom R-organisation Enumeration below Maestro by using the substitution of methyl bunch in compound 20. The R-business enterprise library covered inner Maestro programming have become applied.

\section{EFFECTS AND DISCUSSION \& RESULTS}

Over the preceding years, narcotic receptor has gotten the maximum regular consideration as a important purpose for medicinal drug disclosure of new medicinal pills because of its using centralrole in interceding a variouspharmacological reactions uncovered to social and neurophysiological, as an instance, torment enjoy, addictivebehavior, and gastrointestinal motility frame structure(Spetea et al., 2013b; Pasternak, 2014). As a result, there was large spotlight on the disclosure of novel ligands at narcotic receptor with capability improvement as new and efficient therapeutics(grasping et al., 2013). The crystallization of $\mu$ narcotic receptor shape in 2015 makes it potential to dissect the ligand-receptor restricting partiality and shape-work initiation relationshipsof the human $\mu$ narcotic receptoras the purpose of narcotic pills(Huang et al., 2015). On this work, we gift the outcomes of hypothetical application and blend of sub-atomic showing and restricting proclivity tactics for the revelation of novel new ligands as agonists or opponents at $\mu$ narcotic receptor dynamic website on line. Consequently ofboth computational methodologies, a sum of 27 morphine analogs were docked inner $\mu$ narcotic receptor dynamic internet page to assess the coupling fondness of every simple as appeared in desk 1 .

Table 1. Docking score of substituted derivatives of

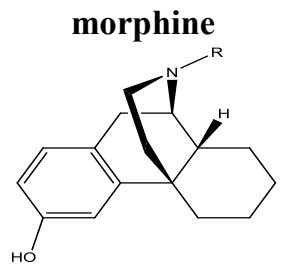

\begin{tabular}{|c|c|c|}
\hline Compound & \multicolumn{1}{|c|}{$\begin{array}{c}\text { Docking } \\
\text { Score in } \\
\mathrm{kcal} / \mathrm{mol}\end{array}$} \\
\hline 1 & & -0.679 \\
\hline 2 & & -0.772 \\
\hline 3 & \\
\hline 4 & \\
\hline
\end{tabular}




\begin{tabular}{|c|c|c|}
\hline 11 & & -0.745 \\
\hline 12 & & -0.757 \\
\hline 13 & 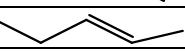 & -0.730 \\
\hline 14 & & -0.779 \\
\hline 15 & & -0.716 \\
\hline 16 & & -0.724 \\
\hline 17 & & -0.756 \\
\hline 18 & & -0.691 \\
\hline 19 & & -0.691 \\
\hline 20 & & -0.816 \\
\hline 21 & & -0.736 \\
\hline 22 & & -0.725 \\
\hline 23 & & -0.697 \\
\hline 24 & & -0.716 \\
\hline 25 & & -0.736 \\
\hline 26 & & -0.709 \\
\hline 27 & Morphine & -0.837 \\
\hline
\end{tabular}

The affinity range was between $-0.662 \mathrm{kcal} / \mathrm{mol}$ for compound 5 to $-0.816 \mathrm{kcal} / \mathrm{mol}$ for compound 20 with $0.837 \mathrm{kcal} / \mathrm{mol}$ for morphine. These findings refer to the unique ability of compound 20 to bind inside the active pocket surrounded by the most important amino acids fig. 1 .

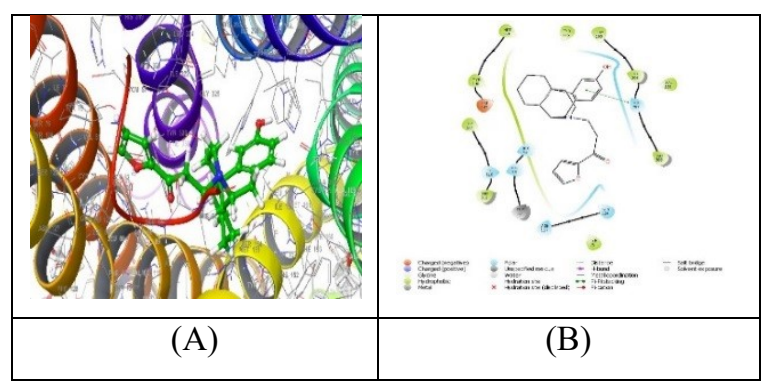

Fig 1. Compound 20 surrounded by the most important amino acids inside active site (A) Compound 20 as ball and stick, protein as ribbon. (B) Ligand interaction of compound 20.

Inside dynamic site, compound 20 tie to HIS297 by $\mathrm{Pi}-\mathrm{Pi}$ stacking communication with phenol ring and encompassed by HIS54, SER55, YCM57, ASP147, TYR148, MET151, TRP293, and ILE296.According to docking result with QSAR model examination and assessment, compound 20 was chosen be the lead compound for the following stage to apply bunch substations at liked. Fig. 2 shows compound 20 (as the most dynamic compound) with alluring and unwanted rules. These rules are marked and shaded by the particular of every region to examine as pursued: Steric mass unwanted close yellow, steric mass attractive close green, positive charge alluring close blue, and negative charge attractive close red.

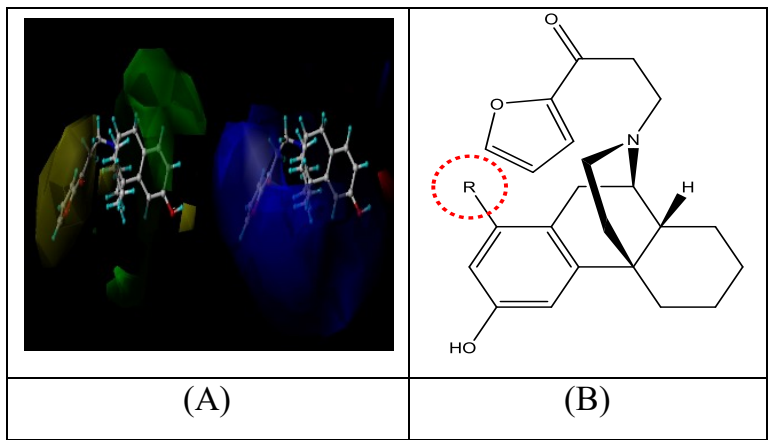

Fig. 2 Compound 20 (A) with desirable and undesirable reigns. (B) Substation position in red cycle.

The green zone is depicted as the best rule to ponder with promising intensity. Starting there, in the fragrant ring at the third position from hydroxy gathering were supplanted with numerous compound gathering from database. After the sub-atomic age by gathering substitution played out, a sum of 978 new morphine analogs were docked,recorded, and the most 20 most elevated analogs are recorded contradicting in table 2.The substitution substation gathering of the most dynamic compound N01 is by 2,6-dichloro phenol at position 3 (meta) of phenol ring. This expanded the coupling partiality to - $11.304 \mathrm{kcal} / \mathrm{mol}$ and docking direction inside the dynamic site encompassed by the significant amino acids Fig. 3.

Table 2. Docking score of the new twenty substituted derivatives of compound 20

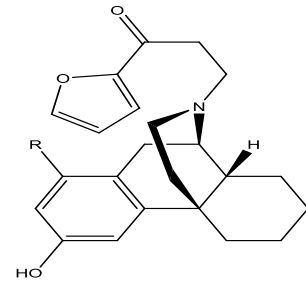

\begin{tabular}{|c|c|c|}
\hline Compound & \multicolumn{1}{|c|}{$\begin{array}{l}\text { Docking } \\
\text { Score in } \\
\mathrm{kcal} / \mathrm{mol}\end{array}$} \\
\hline $\mathrm{N} 01$ & -11.304 \\
\hline $\mathrm{N} 02$ & \\
\hline $\mathrm{N} 03$ & \\
\hline $\mathrm{N} 04$ & \\
\hline
\end{tabular}

Published By 


\begin{tabular}{|c|c|c|}
\hline N06 & M & -10.102 \\
\hline N07 & & -10.003 \\
\hline N08 & & -9.995 \\
\hline N09 & & -9.992 \\
\hline N10 & & -9.930 \\
\hline N11 & & -9.928 \\
\hline $\mathrm{N} 12$ & & -9.915 \\
\hline N13 & & -9.905 \\
\hline N14 & & -9.878 \\
\hline N15 & & -9.875 \\
\hline N16 & & -9.868 \\
\hline N17 & & -9.858 \\
\hline N18 & & -9.850 \\
\hline N19 & & -9.796 \\
\hline $\mathrm{N} 20$ & & -9.772 \\
\hline
\end{tabular}

ligands, these twenty mixes recall as novel concoction frameworks. It is quite perceived that hits willpower bunch substitution approaches usually display desired motion over the mixes in a digital screening models.

\section{CONCLUSION}

In remedy configuration, platform bouncing (or lead leaping) is one of the maximum tremendous method in atomic plan to decorate power or restricting selectivity.The outcome of applying this concept are novel morphine analogs with higher pharmacological profile and better proscribing partiality inner dynamic website online of $\mu$ narcotic receptor inner a scope of variety (- eleven.304 to nine.772) $\mathrm{kcal} / \mathrm{mol}$ for the initial twenty particles. Further natural assessment is needed to comprehend the reactions and pharmacological interest of each new medicinal drug.

\section{REFERENCES}

1. Algamal, Z. Y., Lee, M. H., Al-Fakih, A. M., and Aziz, M. (2015). High-dimensional QSAR expectation of anticancer intensity of imidazo[4,5-b]pyridine subordinates the usage of balanced versatile LASSO. Diary of Chemometrics, 29(10), 547-556.

2. Al-Hasani, R., \&Bruchas, M. R. (2011). Atomic systems of narcotic receptor-subordinate flagging and behavior. Anesthesiology, one hundred fifteen(6), 1363-1381.

3. Allinger, N. (1977). Conformational assessment. One hundred thirty. MM2. A Hydrocarbon stress concern using V1 and V2 Torsional phrases. Diary of the yankee Chemical Society, ninety nine(25), 8127-8134.

4. Benyhe, S. (1994). Morphine: New views in the research of an vintage compound. Existence Sciences, fifty five(thirteen), 969-979.

5. Dark colored, N., and Jacoby, E. (2006). On systems and bouncing in restorative science. Smaller than anticipated critiques in Medicinal Chemistry, 6(11), 1217-1229.

6. ChemDraw. (2016). ChemDraw extremely sixteen.Zero. CambridgeSoft, one hundred Cambridge Park force, Cambridge, MA 02140.

7. Cohen, N. (1996). Manual on Molecular Modeling in Drug layout.

8. Dumitrascuta, M., Ben Haddou, T., Guerrieri, E., Noha, S. M., Schläfer, L., Schmidhammer, H., \&Spetea, M. (2017). Union, Pharmacology, and Molecular Docking studies on 6-Desoxo$\mathrm{N}$ - methylmorphinans as powerful $\mu$-Opioid Receptor Agonists. Diary of Medicinal Chemistry, 60(22), 9407-9412.

9. Eckert, H., \&Bajorath, J. (2007). Sub-atomic likeness research in virtual screening: institutions, constraints and novel strategies. Medication Discovery nowadays, 12(five-6), 225233.

Fig 3. Compound N01 surrounded by the most important amino acids inside active site (A) Compound

20 as ball and stick, protein as ribbon. (B) Ligand interaction of compound N01.

Inner dynamic internet site compound N01 tie thoughts hydroxy accumulating through cooperations, H-connect to HIS54 and with the aid of using salt scaffold to LYS233. Any other connections of this compound with amine bunch through salt extension to ASP147 and Pi-cation to HIS54. Additionally, all of the maximum massive amino acids show up with this compound with the past referenced cooperations. The contemporary of these collaborations is diagnosed with increment the coupling fondness of any particle internal dynamic website online. Conversely among many charming and sincerely understood $\mu$ narcotic receptor

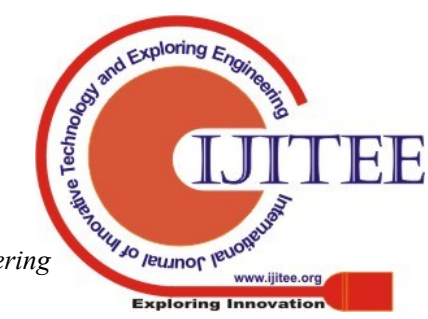


13. Huang, W., Manglik, A., Venkatakrishnan, A. J., Laeremans, T., Feinberg, E. N., Sanborn, A. L., ... Kobilka, B. K. (2015). Auxiliary bits of records into $\mu$-narcotic receptor enactment. Nature, 524(7565), 315-321.

14. Khedkar, S. A., Malde, A. K., Coutinho, E. C., and Srivastava, S. (2007). Pharmacophore displaying in medicinal drug revelation and development: a diagram. Restorative Chemistry (Shariqah (United Arab Emirates)), 3(2), 187-197.

15. Klebe, G. (2006). Digital ligand screening: structures, elements of view and constraints. Remedy Discovery nowadays, 11(thirteen-14), 580-594.

16. Lattanzi, R., Rief, S., Schmidhammer, H., Negri, L., \&Spetea, M. (2018). In vitro and in vivo Pharmacological activities of 14-O-Phenylpropyloxymorphone, a powerful combined $\mathrm{Mu} /$ Delta/Kappa-Opioid Receptor Agonist With decreased Constipation in Mice. Outskirts in Pharmacology, nine, 1002.

17. Lewis, J. W., and Husbands, S. M. (2010). 14-Amino-4,5Epoxymorphinan Derivatives and Their Pharmacological movements (pp. Ninety 3-119). Springer, Berlin, Heidelberg.

18. Lo, Y.- C., Rensi, S. E., Torng, W., and Altman, R. B. (2018). $\mathrm{AI}$ in chemoinformatics and medication revelation. Remedy Discovery today, 23(8), 1538-1546.

19. Neumeyer, J. L., Gu, X.- H., van Vliet, L. A., DeNunzio, N. J., Rusovici, D. E., Cohen, D. J., ... Bidlack, J. M. (2001). Combined $\kappa$ agonists and $\mu$ agonists/Antagonists as capability pharmacotherapeutics for cocaine misuse: union and narcotic receptor restricting partiality of $\mathrm{N}$-substituted subordinates of morphinan. Bioorganic and Medicinal Chemistry Letters, eleven(20), 2735-2740.

20. Nyssen, P., Mouithys-Mickalad, A., Minguet, G., Sauvage, E., Wouters, J., Franck, T., \&Hoebeke, M. (2018). Morphine, a capacity inhibitor of myeloperoxidase movement. Biochimica et Biophysica Acta (BBA) - popular subjects, 1862(10), 2236-2244.

21. Pasternak, G. W. (2014). Sedative pharmacology and help of suffering. Diary of scientific Oncology : legitimate magazine of the american Society of clinical Oncology, 32(sixteen), $1655-1661$

22. Pathan, H., and Williams, J. (2012). Essential narcotic pharmacology: an update. English journal of ache, 6(1), 1116.

23. Rensi, S., and Altman, R. B. (2017). Adaptable Analog are seeking with Kernel PCA Embedded Molecule Vectors. Computational and Structural Biotechnology journal, 15, 320 327.

24. Rocha, G. B., Freire, R. O., Simas, A. M., and Stewart, J. J. P. (2006). RM1: A Reparameterization of AM1 for H, C, N, O, $\mathrm{P}, \mathrm{S}, \mathrm{F}, \mathrm{Cl}, \mathrm{Br}$, and that i. Diary of Computational Chemistry, 27(10), 1101-1111.

25. Skolnick, P., and Volkow, N. D. (2016). Re-stimulating the improvement of pain Therapeutics in light of the Opioid Epidemic. Neuron, ninety two(2), 294-297.

26. Spetea, M., Asim, M. F., Wolber, G., \&Schmidhammer, H. (2013). The $\mu$ narcotic receptor and ligands performing at the $\mu$ narcotic receptor, as therapeutics and capacity therapeutics. Modern-day Pharmaceutical layout, 19(forty two), 74157434.

27. Yin, Z. Y., Li, L., Chu, S. S., solar, Q., Ma, Z. L., and Gu, X. P. (2016). Antinociceptive influences of dehydrocorydaline in mouse fashions of incendiary pain include the narcotic receptor and fiery cytokines. Logical reviews, 6, 27129.

28. Zhao, H. (2007). Framework choice and platform bouncing in lead age: a recovery technological know-how point of view. Remedy Discovery these days, 12(three-4), 149-one hundred fifty five.

29. Zhao, H., Xin, Z., Liu, G., Schaefer, V. G., Falls, H. D., Kaszubska, W., ... Sham, H. L. (2004). Disclosure of Tetralin Carboxamide boom Hormone Secretagogue Receptor Antagonists with the aid of Scaffold Manipulation. Diary of Medicinal Chemistry, forty seven(27), 6655-6657. 